\title{
Structural changes in sugarcane bagasse cellulose caused by enzymatic hydrolysis
}

\author{
Makiko Imai ${ }^{1}$, Yoshiki Horikawa ${ }^{2}$, Shingo Kiyoto ${ }^{1}$, Tomoya Imai ${ }^{1}$ and Junji Sugiyama ${ }^{1,3^{*} \text { (D) }}$
}

\begin{abstract}
Cellulose I is not completely saccharified to glucose at a low cellulase concentration. In this study, sugarcane cellulose saccharification residues were investigated. Transmission electron microscopy images indicated that the cellulose microfibrils became shorter in the early stages of saccharification and gradually became narrower. The degree of polymerization also decreased in the early stages of saccharification. Cellulose saccharification residues were deuterated by immersing them in deuterium oxide. Infra-red spectra of the deuterated residues indicated that the deuterated hydroxyl group ratio decreased as saccharification progressed. This indicated that cellulose microfibrils were hydrolyzed in their hydrophobic planes by cellulase as if the surfaces were scraped. The increase of hydrophobic planes caused microfibril aggregation, poor accessibility of cellulase to the microfibrils, and a low saccharification rate.
\end{abstract}

Keywords: Cellulose, Cellulase, Deuteration, Hydrophobic plane, Hydrophilic plane, SAXS

\section{Introduction}

Sugarcane has been cultivated to produce sugar for a long time. Increasing amount of sugarcanes has been used to produce bioethanol over the past few decades. Producing bioethanol from cellulose economically requires saccharification to be achieved using the smallest possible amount of enzymes. However, cellulose I (native cellulose) is not completely saccharified to glucose at a low cellulase concentration [1]. It has been suggested in numerous studies that the low saccharification rate is caused by the non-specific adsorption of enzymes to substrates (making the enzymes inactive) [2-5], enzyme deactivation through other processes [6], inhibition caused by the products [7], and the effects of certain cellulose characteristics. It has been suggested that the problem of low saccharification rates may be related to using substrates with high hemicellulose contents, high lignin contents, and certain surface pore sizes [2], but the saccharification rate is low at a low cellulase concentration even for pure cellulose I (with hemicellulose and

\footnotetext{
*Correspondence: sugiyama.junji.6m@kyoto-u.ac.jp

${ }^{1}$ Research Institute for Sustainable Humanosphere, Kyoto University,

Gokasho, Uji, Kyoto 611-0011, Japan

Full list of author information is available at the end of the article
}

lignin removed). However, cellulose $\mathrm{III}_{\mathrm{I}}$ is almost completely hydrolyzed at low enzyme concentrations [1]. Cellulose III $_{\mathrm{I}}$ is produced from cellulose I but has a different crystalline form from cellulose I [8]. The saccharification limit is therefore caused by a combination of the hemicellulose and lignin contents and the cellulose I structure.

In the study described here, cellulose residues after saccharification were analyzed, because we assumed that a poor saccharification rate will be related to the structures of the residue. Cellulose residues were first analyzed by transmission electron microscopy (TEM) and by making small-angle X-ray scattering (SAXS) measurements to assess the morphologies of the residues. Cellulose residues were then deuterated to allow the hydrophilicities of the residues to be determined. Cellulose has been deuterated in numerous previous studies. Infra-red (IR) spectra of the deuterated cellulose were acquired. The $\mathrm{OH}$ stretching bands at $3500-3300 \mathrm{~cm}^{-1}$ were completely translated to wavelengths $\sim 1000 \mathrm{~cm}^{-1}$ lower without any loss of resolution [9], and the deuteration ratio was easily determined [10]. Only $\mathrm{OH}$ groups on the surfaces and in disordered regions are deuterated when cellulose is stored in deuterium oxide [11], but $\mathrm{OH}$ groups even in crystalline regions are deuterated when cellulose is

\section{Springer Open}

(c) The Author(s) 2020. This article is licensed under a Creative Commons Attribution 4.0 International License, which permits use, sharing, adaptation, distribution and reproduction in any medium or format, as long as you give appropriate credit to the original author(s) and the source, provide a link to the Creative Commons licence, and indicate if changes were made. The images or other third party material in this article are included in the article's Creative Commons licence, unless indicated otherwise in a credit line to the material. If material is not included in the article's Creative Commons licence and your intended use is not permitted by statutory regulation or exceeds the permitted use, you will need to obtain permission directly from the copyright holder. To view a copy of this licence, visit http://creativeco mmons.org/licenses/by/4.0/. 
treated with a sodium deuteroxide solution at a high temperature and a high pressure [8]. In the study described here, a saccharification residue was stored in deuterium oxide under conditions that caused only $\mathrm{OH}$ groups on the surfaces and in disordered regions to become deuterated, to allow the residue surfaces to be analyzed.

\section{Materials and methods}

\section{Preparation of bagasse cellulose}

Sugarcane bagasse powder that had been passed through a $1-\mathrm{mm}$ sieve was treated with acidified sodium chlorite solution at $70^{\circ} \mathrm{C}$ using the Jayme-Wise method [12]. This process was repeated 5 times until IR absorption bands at 1510 and $1600 \mathrm{~cm}^{-1}$ (assigned to aromatic skeletal vibrations of the lignin) had completely disappeared. The sample was then boiled in 5\% sodium hydroxide for $2 \mathrm{~h}$ to remove hemicellulose. Obtained samples were then processed twice using a disk mill to be fibrillated.

\section{Enzymatic hydrolysis}

The enzyme Accellerase 1500 (DuPont, Wilmington, DE, USA) was used in the study. Accellerase 1500 is produced using a genetically modified strain of Trichoderma ree$s e i$. Bagasse cellulose (10 mg on a dry matter basis) was placed in a test tube, then $1 \mathrm{~mL}$ of $100 \mathrm{mM}$ acetate buffer (pH 5.0) and $10 \mu \mathrm{g}$ of Accellerase 1500 were added. The mixture was incubated at $50{ }^{\circ} \mathrm{C}$ in a water bath with shaking at $150 \mathrm{rpm}$. The D-glucose concentration in the supernatant was measured $1,24,72,142,168$, and $196 \mathrm{~h}$ after incubation started using a D-glucose assay kit (Roche, Basel, Switzerland). The saccharification rate was defined as the ratio between the measured amount of glucose and the total amount of glucose calculated from the amount of cellulose present, expressed as a percentage.

\section{Degree of polymerization}

The weight-averaged molecular weight of cellulose was estimated using the method described by Horikawa et al. [13] modified as described by Hallac et al. [14]. Cellulose was derivatized using a tricarbanilation process performed using anhydrous pyridine and phenyl isocyanate. The products were dissolved in tetrahydrofuran, and the soluble material was subjected to the procedure described below. Gel permeation chromatography analysis was performed using a high-speed liquid chromatography system. Calibration curves were produced using polystyrene standards. The degree of polymerization (DP) was calculated by dividing the weight-averaged molecular weight by 519 (the molecular weight of the cellulose tricarbanilate repeating unit).

\section{TEM}

The cellulose residue after the saccharification had been performed was washed thoroughly with distilled water and suspended in water. The suspension was then applied to a grid covered with carbon. Excess water was removed with a filter paper, and then the grid was negatively stained with $2 \%$ uranyl acetate. Photographs of the sample were acquired using a 2000EX TEM system (JEOL, Tokyo, Japan) using a voltage of $100 \mathrm{kV}$.

The lengths and widths of the cellulose microfibril residues after the saccharification for 1,24 , and $196 \mathrm{~h}$ were determined from the TEM images using Image J software.

\section{SAXS measurement}

Slurries of nanofibrillated cellulose before and after the saccharification for $142 \mathrm{~h}$ were subjected to SAXS measurements using the BL8S3 beamline at the Aichi Synchrotron Radiation Center (Aichi, Japan). After removing of enzymes from the cellulose residues by washing with $0.2 \%$ sodium hydroxide and water, the cellulose concentrations in the slurries of the samples that had been saccharified for 0 and $142 \mathrm{~h}$, determined using the anthrone-sulfuric acid reaction described previously [15], were $\sim 0.39 \% \mathrm{w} / \mathrm{v}$ and $\sim 0.24 \% \mathrm{w} / \mathrm{v}$, respectively. To perform a measurement, a slurry sample was loaded into a liquid cell (made in-house) with a $3-\mathrm{mm}$ optical path and 0.02-mm-thick quartz plate windows. The cell was placed in a temperature-controlled sample holder. SAXS measurements were performed using X-rays with an energy of $13.5 \mathrm{keV}$ (wavelength $0.092 \mathrm{~nm}$ ) and a sample-to-camera distance of $2.1 \mathrm{~m}$. The parameters relating to the geometry of the experiment were calibrated using silver behenate. A scattering pattern was recorded using an R-Axis IV++ imaging plate detector (Rigaku, Tokyo, Japan) using a $600 \mathrm{~s}$ exposure time. Azimuthal integration of the scattering pattern was performed using the beamline program to give one-dimensional data for the scattering intensity $(I)$ based on the scattering vector $q=(4 \pi \cdot \sin$ $\theta) / \lambda$. The intensity was normalized by the X-ray absorbance estimated from the photon count measured using ionizing chambers in front of and behind the sample. The one-dimensional data were visualized and analyzed using Python 3.7.0 software.

\section{Acquisition of IR spectra for deuterated bagasse cellulose}

Saccharification residues after $0,24,72$, and $196 \mathrm{~h}$ of incubation were treated with $0.2 \%$ sodium hydroxide to remove the enzymes, and then each sample was washed thoroughly with distilled water. Each sample was then washed twice with deuterium oxide $(99.9 \%$ D atoms; 


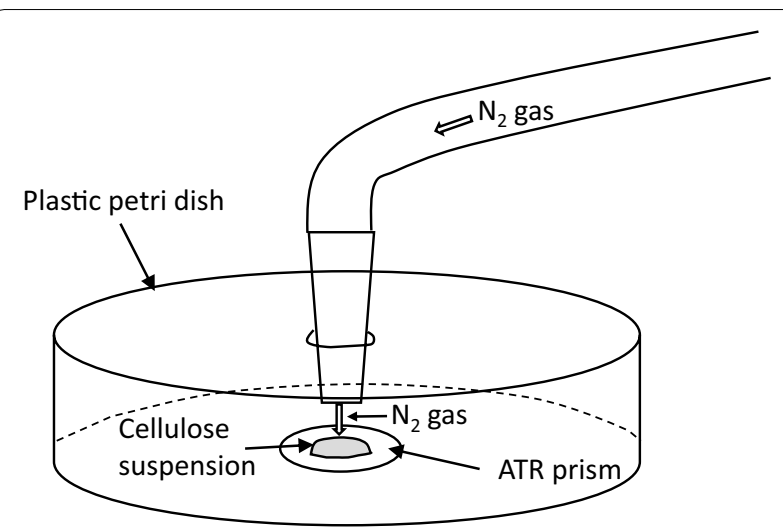

Fig. 1 Schematic representation of the apparatus used to acquire an infra-red spectrum in attenuated total reflection mode

Sigma-Aldrich, St. Louis, MO, USA) and then stored in deuterium oxide at room temperature for $24 \mathrm{~h}$.

The Fourier transform (FT) IR spectrum of each sample was acquired using a Frontier FT-IR spectrometer (PerkinElmer, Waltham, MA, USA). The wave number range for a spectrum was $500-4000 \mathrm{~cm}^{-1}$, and the resolution was $4 \mathrm{~cm}^{-1}$. For each spectrum, 16 scans were performed in attenuated total reflection (ATR) mode. The ATR prism was covered with a plastic Petri dish with a small hole in the center (Fig. 1). The cellulose suspension to be analyzed $(2.5 \mu \mathrm{L})$ was applied to the ATR prism through the hole. Ultra-high purity nitrogen that had been passed through a liquid nitrogen trap was blown over the sample from the hole to dry it. An IR spectrum was acquired $5 \mathrm{~min}$ after the absorbance characteristics of deuterium oxide were last detected. The spectrum was smoothed and baseline corrected, then the spectrum was normalized to the heights of the $\mathrm{CH}$ and $\mathrm{CH}_{2}$ absorbance peaks. The OD ratio was calculated using the equation shown below [10].

$$
\begin{aligned}
& \text { OD ratio }(\%)=100 \times\left(A_{\mathrm{OD}} /\left(A_{\mathrm{OH}}+A_{\mathrm{OD}}\right)\right) \\
& A_{\mathrm{OD}}=\text { Height of the OD absorbance peak }\left(\sim 2500 \mathrm{~cm}^{-1}\right) \\
& A_{\mathrm{OH}}=\text { Height of the } \mathrm{OH} \text { absorbance peak }\left(\sim 3330 \mathrm{~cm}^{-1}\right)
\end{aligned}
$$

\section{Results and discussion Enzymatic hydrolysis}

It has previously been found that cellulose is not completely enzymatically hydrolyzed at low cellulase concentration [1].

In this study, the saccharification rate reached a maximum at $142 \mathrm{~h}$ (Fig. 2), as was found previously [1]. The saccharification rate was lower at $196 \mathrm{~h}$ than at $168 \mathrm{~h}$, but the difference was not significant.

\section{Weight-averaged DP}

The hydrolysis of cellulose by endoglucanase causes the weight-averaged $\mathrm{DP}\left(\mathrm{DP}_{\mathrm{w}}\right)$ to decrease rapidly [13]. This is because endoglucanase cuts cellulose chains at random points in amorphous regions. In this study, the $\mathrm{DP}_{\mathrm{w}}$ decreased rapidly in the first hour of incubation but the saccharification rate remained below $20 \%$ at that time (Fig. 2). This indicated that the cellulose chains had been cut into shorter molecules but that not much glucose was produced at the beginning of the hydrolysis process. The $\mathrm{DP}_{\mathrm{w}}$ then slowly decreased but the saccharification rate increased rapidly, mainly through the actions of two cellobiohydrolases.

\section{TEM}

The cellulose microfibrils before saccharification had been performed were more than several micrometers long. The ends of the microfibrils could not be seen, so it was not possible to determine the actual lengths of the microfibrils (Fig. 3a). The microfibrils had become drastically shorter after $1 \mathrm{~h}$ of saccharification (Fig. 3b), and the microfibrils were slightly shorter still after $196 \mathrm{~h}$ of saccharification (Fig. 3c). The lengths and widths of the microfibrils were determined using Image J software. The microfibrils became shorter during the first phase of the saccharification process, which lasted $\sim 24 \mathrm{~h}$. The saccharification process caused the cellulose microfibrils to become both shorter and narrower (Fig. 4). This agreed with the decrease in $\mathrm{DP}_{\mathrm{w}}$.

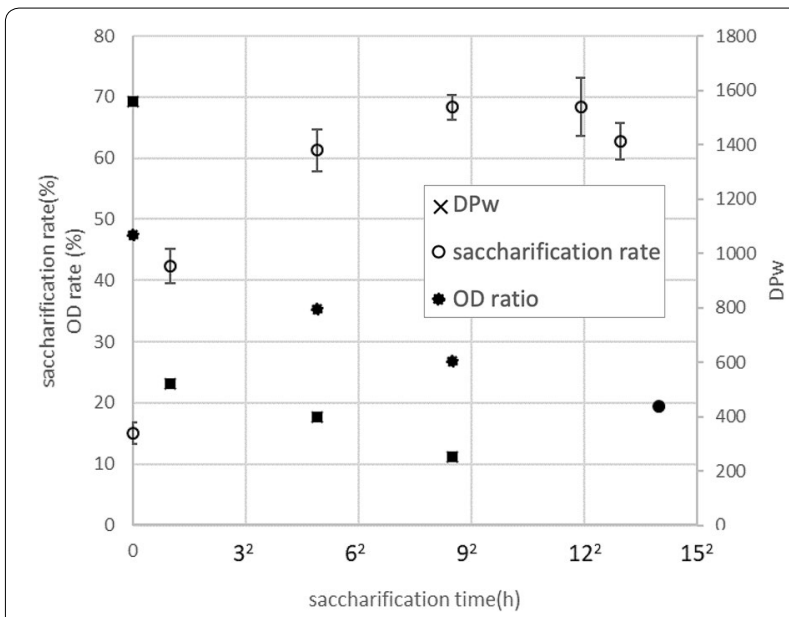

Fig. 2 Saccharification rates, weight-averaged degrees of polymerization $\left(\mathrm{DP}_{\mathrm{w}} \mathrm{s}\right)$, and $\mathrm{OD}$ ratios for bagasse cellulose hydrolyzed using Accellerase 1500. Open circles are saccharification rates, filled circles are $\mathrm{OD}$ ratios, and crosses are $\mathrm{DP}_{\mathrm{w}}$ 


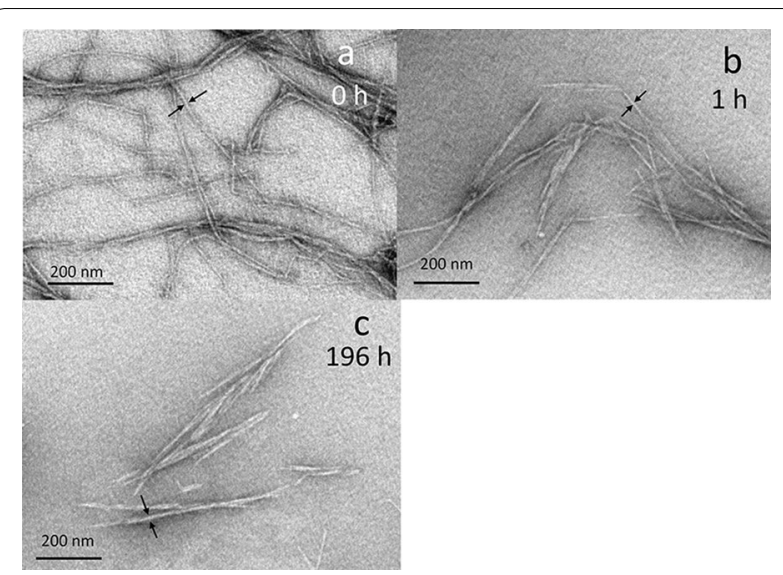

Fig. 3 Transmission electron microscopy images of negative stained bagasse cellulose $\mathbf{a}$ before saccharification, $\mathbf{b}$ after saccharification for $1 \mathrm{~h}$, and c after saccharification for $196 \mathrm{~h}$. Each pair of arrows indicates the measured width

The saccharification residues became aggregated (Fig. 3b, c). Large cellulose aggregates were also visible by eye when the saccharification process had been occurring for $24 \mathrm{~h}$.

\section{SAXS analysis}

Structural changes in the cellulose caused by cellulase were identified by performing SAXS analysis of an

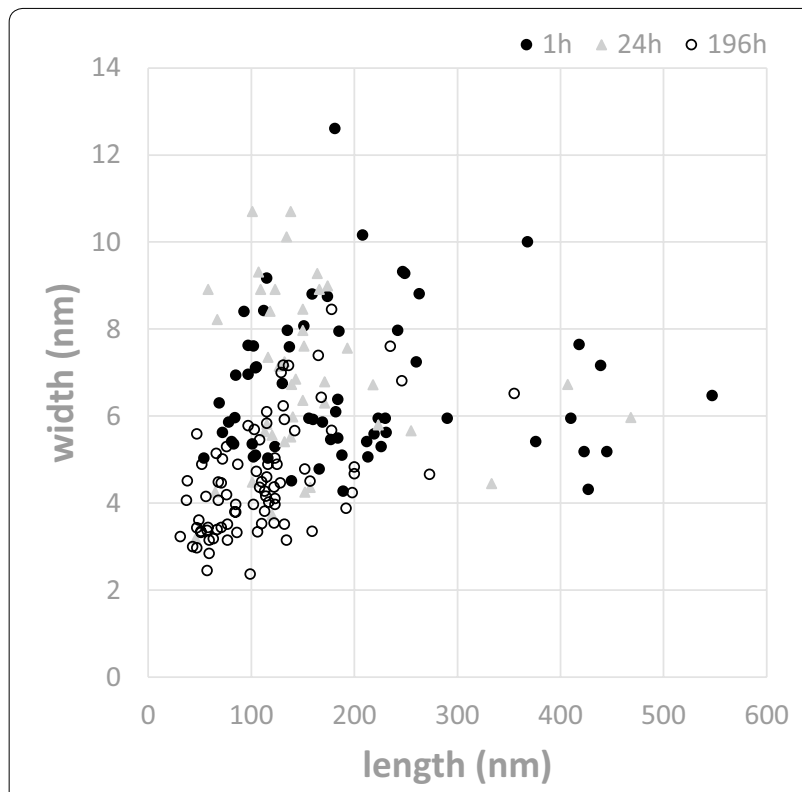

Fig. 4 Lengths and widths of saccharified cellulose residues. Filled black circles are data for cellulose saccharified for $1 \mathrm{~h}$, filled gray circles are data for cellulose saccharified for $24 \mathrm{~h}$, and open circles are data for cellulose saccharified for $196 \mathrm{~h}$ aqueous sample. The cellulose residue after $142 \mathrm{~h}$ of saccharification was subjected to SAXS analysis. The saccharification rate had reached a maximum at $142 \mathrm{~h}$, as shown in Fig. 2, so it was reasonable to use the residue after $142 \mathrm{~h}$ of saccharification as a substitute for the residue after $196 \mathrm{~h}$ of saccharification. The $q$-region of the SAXS signal was limited, so we qualitatively interpreted the $q-I$ curve shown in Fig. 5. The SAXS data were prepared by subtracting the SAXS profile of pure water from the SAXS profile of the aqueous residue sample.

A shoulder feature was found at around $q=1 \mathrm{~nm}^{-1}$ for cellulose both before and after treatment with cellulase. This could be explained by the presence of highly dispersed cellulose microfibrils with sharp interfaces with the solvent, as was found in previous studies [16, 17]. The higher $q$-region of this shoulder feature (1.5$2.5 \mathrm{~nm}^{-1}$ ) was successfully fitted using the power law in the form $I(q) \propto q^{-D}$, where $D=4$ for both samples, as shown in Fig. 5. This could be interpreted as indicating that scattering occurred at the cellulose interface with a surface fractal dimension of 2 (i.e., $6-D$ ). The cellulose interface (i.e., the cellulose microfibril surface) was assumed to be, on average, smooth before and after hydrolysis by cellulase. The lack of change in this parameter indicated that the surfaces of the cellulose microfibrils that remained after $142 \mathrm{~h}$ of cellulase hydrolysis were as smooth as the surfaces of the microfibrils before they were hydrolyzed. A similar study with more frequent sampling times will need to be performed to allow a more detailed interpretation to be made.

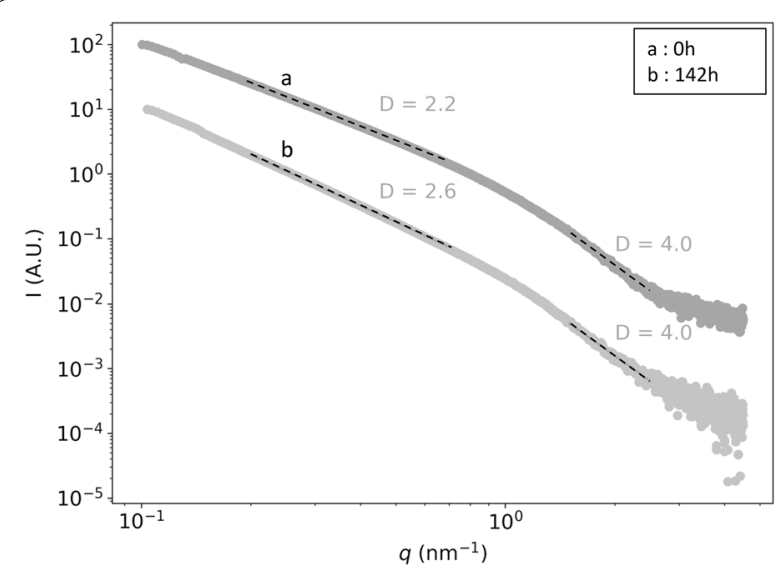

Fig. 5 Small-angle X-ray scattering data shown as a double-logarithmic $q$ - $/$ plot for nanofibrillated cellulose samples 0 and $142 \mathrm{~h}$ after cellulase hydrolysis started. a Before saccharification. b After saccharification for $142 \mathrm{~h}$. Circles are measured data. Straight lines were fitted to the results using the power law $I(q) \propto q^{-D}$, and the $D$ values obtained are shown 
Another important feature of the SAXS profile was monotonic scattering decay in the range $q=0.2-$ $0.7 \mathrm{~nm}^{-1}$. This $q$-region was fitted to the power law $I(q)$ $\propto q^{-D}$, and the values of $D$ for the 0 - and 142-h hydrolysis time samples were 2.2 and 2.6, respectively. Perfectly dispersed plant cellulose microfibrils would be expected to exhibit scattering decay along a $q^{-1}$ asymptote in this $q$-region, as found in a previous study [17]. The $D$ values used in this study were $>2$, clearly indicating that the cellulose microfibrils were aggregated rather than dispersed. Hydrolysis by cellulase clearly increased the $D$ value in this $q$-region. The increase in the $D$ value indicated that the structures at the size corresponding to the $q$ values became denser. This change in the SAXS profile probably indicated that cellulose microfibrils were more densely packed after hydrolysis by cellulase than before. This agreed with the conclusion drawn from the TEM images that cellulase hydrolysis removed dispersed long microfibrils and caused cellulose microfibrils with similar lengths ( $200 \mathrm{~nm})$ to form aggregates (Fig. 3a, c).

\section{IR spectra of deuterated bagasse cellulose}

Cellulose has numerous hydroxyl groups that form intracellular and intercellular hydrogen bonds with each other. However, free hydroxyl groups are exposed on cellulose microfibril surfaces, and the hydrogen atoms in these groups can easily be replaced with deuterium when the cellulose is stored in deuterium oxide. It is difficult to acquire an IR spectrum of deuterated cellulose because the OD groups in deuterated cellulose easily return to being $\mathrm{OH}$ groups when the system is exposed to $\mathrm{H}_{2} \mathrm{O}$ in the air. IR spectra of deuterated cellulose in deuterium oxide vapor have been acquired $[11,18]$. In this study, a cellulose suspension in deuterium oxide was applied to an ATR prism and a spectrum was acquired while the cellulose was enveloped in a dry nitrogen atmosphere. No absorbance was found at $\sim 2500 \mathrm{~cm}^{-1}$ (absorbance by OD) before the cellulose was deuterated (Fig. 6). However, the spectrum of the deuterated cellulose both before and after $196 \mathrm{~h}$ of saccharification contained an OD absorption peak (Fig. 6). As more saccharification occurred, the OD ratio decreased from $>40$ to $<20 \%$ (Fig. 2). It has previously been found that cellulase binds to hydrophobic planes of cellulose and then starts to hydrolyze the cellulose $[19,20]$. The exposed hydroxyl group ratio decreased and more hydrophobic planes became exposed as cellulose I was hydrolyzed from the hydrophobic planes (Fig. 7). Cellulose I has two crystal forms, cellulose $I_{\alpha}$ and cellulose $I_{\beta}$ [21]. Cellulose $I_{\beta}$ is dominant in sugarcane, a higher plant. The cellulose microfibrils are synthesized by the cellulose synthase enzyme complex visualized in the plasma membrane as rosettes. It has been proposed that the microfibril

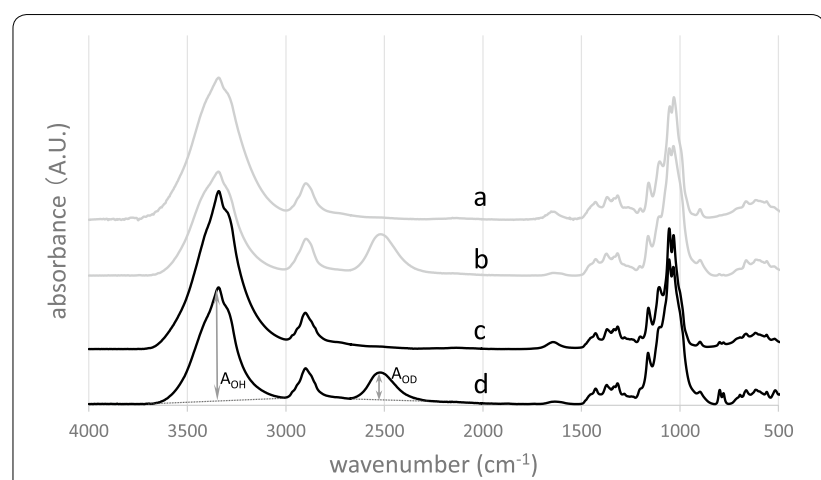

Fig. 6 Infra-red spectra of bagasse cellulose a before hydrolysis and before deuteration, b before hydrolysis and after deuteration, $\mathrm{c}$ after hydrolysis for $196 \mathrm{~h}$ and before deuteration, and d after hydrolysis for $196 \mathrm{~h}$ and after deuteration

consists of 36 molecular chains [22]. In recent years, various models (e.g., 18 molecular chains, 24 molecular chains) have been proposed by some researchers [23-25]. In this study, theoretical OD ratios were calculated for the conventional 36 molecular chains' model. A cellulose microfibril consisting of 36 molecules will have the crosssection before saccharification shown in Fig. 7a. The saccharification rate was $15 \%$, and the microfibrils became shorter after an hour of saccharification. The cellulose molecules have been hydrolyzed from two hydrophobic planes, and the cross-sections would have the structures shown in Fig. 7b. The microfibrils were then saccharified further and the hydrophobic plane areas increased. Once the saccharification reached the limit, the short microfibrils aggregated through hydrophobic effects (Fig. 7c). This was consistent with the cellulose residue aggregation observed by TEM. The ratio of hydroxyl groups exposed on the outsides of the microfibrils was calculated (Fig. 8). The ratio before saccharification was $31 \%$, although the ratio of deuterated hydroxyl groups determined from the IR spectrum was $47 \%$. The discrepancy was caused by microfibrils having some disordered parts with hydroxyl groups that could be deuterated. As saccharification progressed, the ratio of exposed hydroxyl groups gradually decreased to $\sim 20 \%$, as did the ratio of deuterated hydroxyl groups (Fig. 8). The accessibility of the cellulose to cellulase decreased as the hydrophilicity decreased and aggregation increased, and this explained the cellulose residues becoming more difficult to hydrolyze. Cellulose $\mathrm{III}_{\mathrm{I}}$ can be more easily hydrolyzed than cellulose I, and does not have a saccharification limit [1]. This is because cellulose III $_{I}$ has wider moderately hydrophobic planes that enzymes can become attached to and hydrolyze [26]. Moderately hydrophobic planes also have free hydroxyl groups on their surfaces (Fig. 9). The ratio of free hydroxyl groups on moderately hydrophobic 
plane surfaces will probably not decrease even though enzymes will hydrolyze cellulose $\mathrm{III}_{\mathrm{I}}$ along its planes. It is likely that the remaining hydroxyl groups on cellulose
$\mathrm{III}_{\mathrm{I}}$ crystals prevent them from spontaneous aggregation, which leads to the complete degradation. Recently, it was reported that the saccharification residue of cellulose II

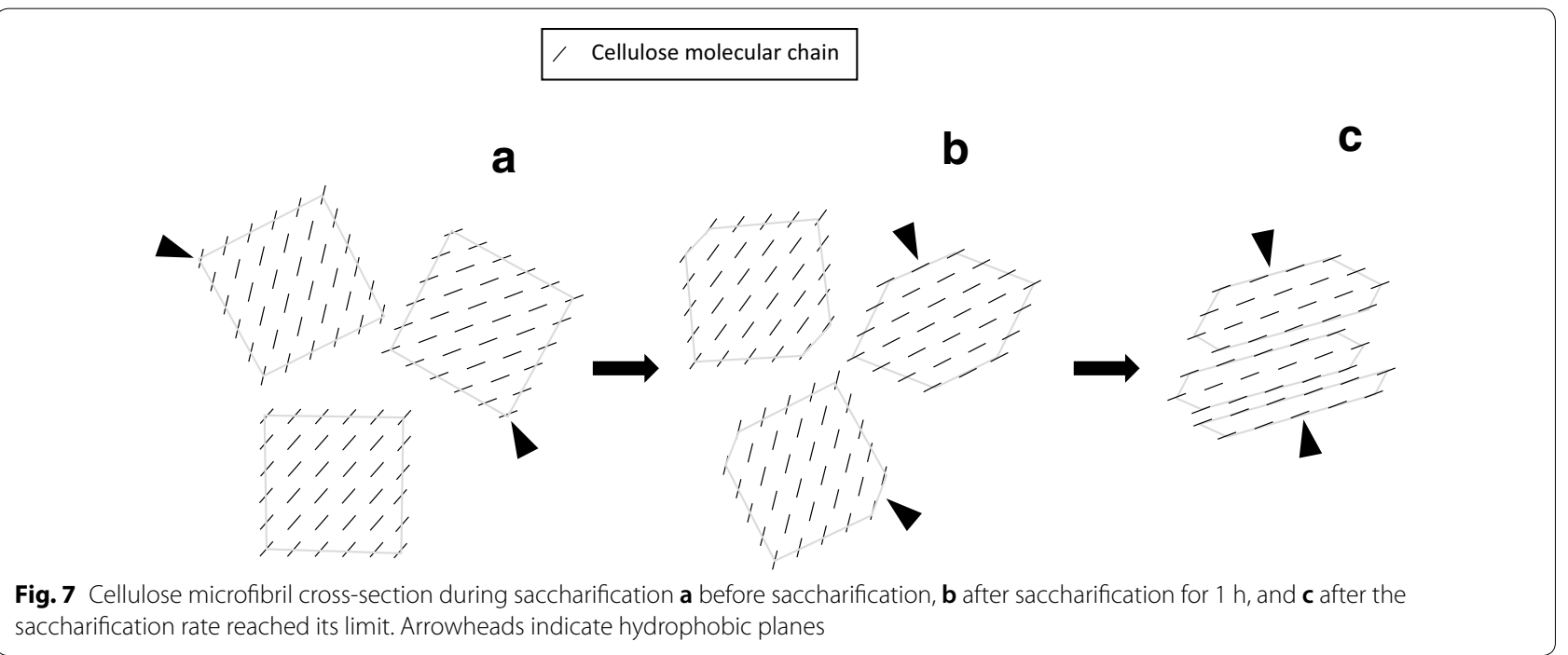

saccharification rate reached its limit. Arrowheads indicate hydrophobic planes

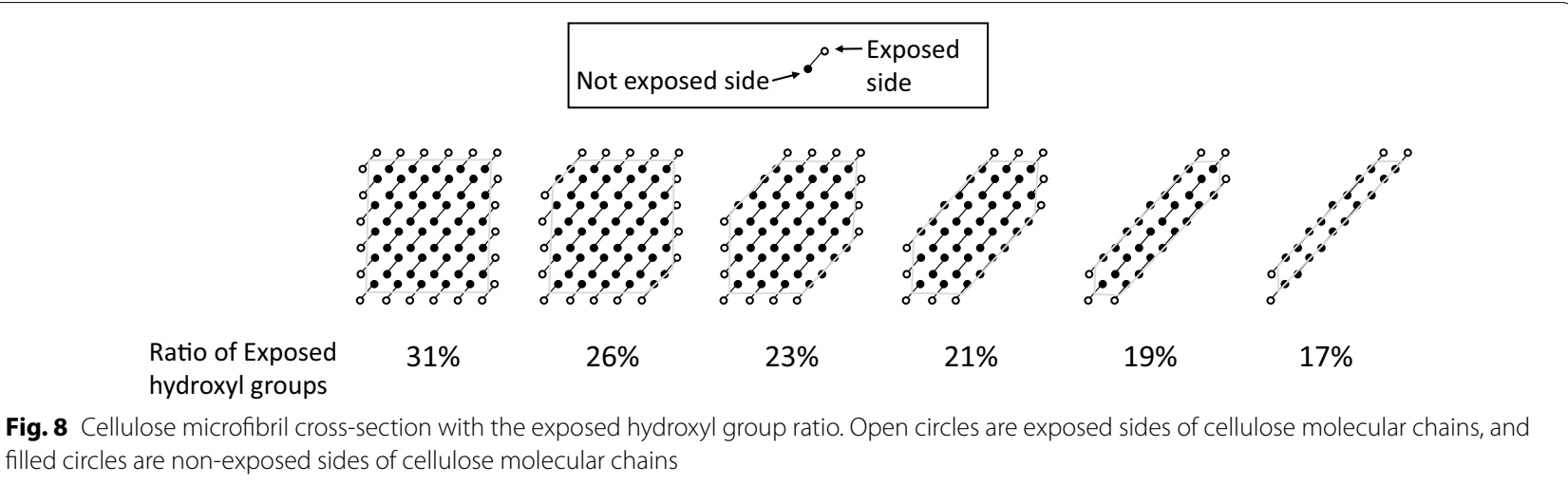

Fig. 8 Cellulose microfibril cross-section with the exposed hydroxyl group ratio. Open circles are exposed sides of cellulose molecular chains, and filled circles are non-exposed sides of cellulose molecular chains

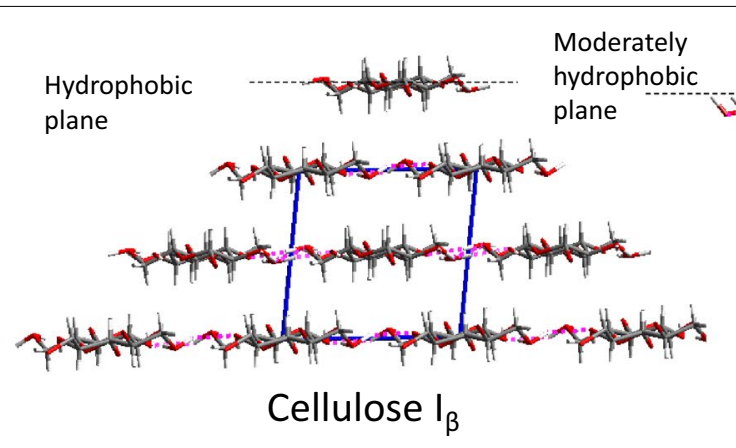

a

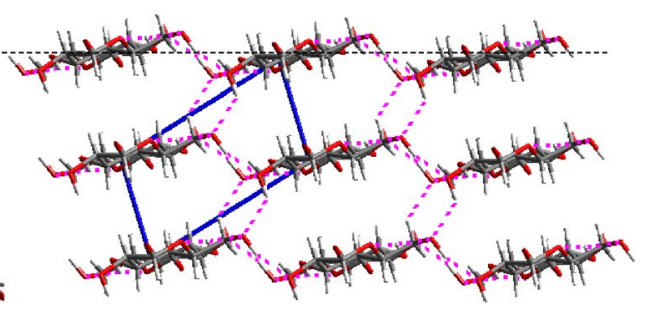

Cellulose IIII

b

Fig. 9 Crystal structures of cellulose $I_{\beta}$ and cellulose IIII (modified from The cellulose microfibril and its polymorphs [27]). a Cross-section of cellulose $\mathrm{I}_{\beta}$. b Cross-section of cellulose $I I I_{\mid}$ 
at a low cellulase concentration was cellulose I [1]. This is a case of the aggregation of cellulose I by increase of hydrophobic planes.

\section{Conclusions}

Sugarcane bagasse cellulose microfibrils decreased in length to $\sim 200 \mathrm{~nm}$ in the early stages of saccharification and also gradually became narrower. Cellulose I was hydrolyzed from the hydrophobic planes, and the hydrophilicity decreased as saccharification proceeded. Aggregation of the saccharification residues was observed by TEM. This was supported by SAXS analysis results, including of a complete cellulose suspension. Aggregation was caused by hydrophobic effects derived from exposed wide hydrophobic planes. The results indicated that exposure of hydrophobic planes and hydrophilicity are required for enzymatic saccharification to occur. Decreasing hydrophilicity during saccharification is probably one of the reasons for enzymatic saccharification of cellulose is limited.

\begin{abstract}
Abbreviations
ATR: Attenuated total reflection; DP: Degree of polymerization; $\mathrm{DP}_{\mathrm{w}}$ : Weightaveraged degree of polymerization; FT: Fourier transform; IR: Infra-red; SAXS: Small-angle X-ray scattering; TEM: Transmission electron microscopy.
\end{abstract}

\section{Acknowledgements}

The study was conducted in the framework of the New Energy and Industrial Technology Development Organization (NEDO) project entitled: "Construction of Innovative Saccharifying Enzyme producing Microorganism and Development of Manufacturing of the Enzyme for the Biofuel Commercialization". We thank Dr. Yoshinori Kobayashi (Japan Bioindustry) for supplying the sugarcane bagasse used in the study. Cellulose milling was performed by Dr. Kentaro Abe (Kyoto University). The SAXS experiments were performed at the BL8S3, at the Aichi Synchrotron Radiation Center, Aichi Science \& Technology Foundation, Aichi, Japan (proposal no. 201806093). A part of study was supported by the RISH Cooperative Research (ADAM) and RISH Mission Research II frameworks. We thank Gareth Thomas, Ph.D., from Edanz Group (http://www.edanzediti ng.com/ac) for editing a draft of this manuscript.

\section{Authors' contributions}

MI and JS designed the study. MI was a major contributor in writing the manuscript and performing the saccharification procedures, TEM observations, and IR measurements. The bagasse cellulose was prepared and the DP measurements were performed by $\mathrm{YH}$, and the small-angle $\mathrm{X}$-ray scattering experiments were performed by SK and TI. All authors read and approved the final manuscript.
\end{abstract}

\section{Funding}

This study was supported by the New Energy and Industrial Technology Development Organization (NEDO) project entitled "Construction of Innovative Saccharifying Enzyme-producing Microorganisms and Development for Manufacturing of the Enzyme for the Biofuel Commercialization".

\section{Availability of data and materials}

The datasets generated during and/or analyzed during the current study are available from the corresponding author on reasonable request.

\section{Competing interests}

The authors declare that they have no competing interests.

\section{Author details}

1 Research Institute for Sustainable Humanosphere, Kyoto University, Gokasho, Uji, Kyoto 611-0011, Japan. ${ }^{2}$ Institute of Agriculture, Tokyo University of Agriculture and Technology, Saiwai-cho, Fuchu, Tokyo 183-8509, Japan. ${ }^{3}$ College of Materials Science and Engineering, Nanjing Forestry University, Nanjing 210037, China.

Received: 8 November 2019 Accepted: 12 February 2020

Published online: 22 February 2020

\section{References}

1. Horikawa Y, Konakahara N, Imai T et al (2013) The structural changes in crystalline cellulose and effects on enzymatic digestibility. Polym Degrad Stab 98:2351-2356. https://doi.org/10.1016/j.polymdegradstab .2013.08.004

2. Grethlein HE, Converse AO (1991) Common aspects of acid prehydrolysis and steam explosion for pretreating wood. Bioresour Technol 36:77-82. https://doi.org/10.1016/0960-8524(91)90101-O

3. Lou H, Wang M, Lai H et al (2013) Reducing non-productive adsorption of cellulase and enhancing enzymatic hydrolysis of lignocelluloses by noncovalent modification of lignin with lignosulfonate. Bioresour Technol 146:478-484. https://doi.org/10.1016/j.biortech.2013.07.115

4. Palonen H, Tjerneld F, Zacchi G, Tenkanen M (2004) Adsorption of Trichoderma reesei $\mathrm{CBH}$ I and EG II and their catalytic domains on steam pretreated softwood and isolated lignin. J Biotechnol 107:65-72. https:// doi.org/10.1016/j.jbiotec.2003.09.011

5. Saini JK, Patel AK, Adsul M, Singhania RR (2016) Cellulase adsorption on lignin: a roadblock for economic hydrolysis of biomass. Renew Energy 98:29-42. https://doi.org/10.1016/j.renene.2016.03.089

6. Gunjikar TP, Sawant SB, Joshi JB (2001) Shear deactivation of cellulase, exoglucanase, endoglucanase, and beta-glucosidase in a mechanically agitated reactor. Biotechnol Prog 17:1166-1168. https://doi.org/10.1021/ bp010114u

7. Atreya ME, Strobel KL, Clark DS (2016) Alleviating product inhibition in cellulase enzyme Cel7A. Biotechnol Bioeng 113:330-338. https://doi. org/10.1002/bit.25809

8. Wada M, Okano T, Sugiyama J (1997) Synchrotron-radiated X-ray and neutron diffraction study of native cellulose. Cellulose 4:221-232. https://doi. org/10.1023/A:1018435806488

9. Nishiyama Y, Isogai A, Okano T et al (1999) Intracrystalline deuteration of native cellulose. Macromolecules 32:2078-2081. https://doi.org/10.1021/ ma981563m

10. Horikawa Y, Sugiyama J (2008) Accessibility and size of Valonia cellulose microfibril studied by combined deuteration/rehydrogenation and FTIR technique. Cellulose 15:419-424. https://doi.org/10.1007/s1057 0-007-9187-z

11. Hofstetter K, Hinterstoisser B, Salmén L (2006) Moisture uptake in native cellulose - the roles of different hydrogen bonds: a dynamic FT-IR study using Deuterium exchange. Cellulose 13:131-145. https://doi. org/10.1007/s10570-006-9055-2

12. Wise LE, Murphy M, D'Addieco AA (1946) Chlorite holocellulose, its fractionation and bearing on summative wood analysis and studies on the hemicelluloses. Pap Trade 122:35-43

13. Horikawa Y, Imai T, Abe K et al (2016) Assessment of endoglucanase activity by analyzing the degree of cellulose polymerization and highthroughput analysis by near-infrared spectroscopy. Cellulose 23:15651572. https://doi.org/10.1007/s10570-016-0927-9

14. Hallac BB, Sannigrahi P, Pu Y et al (2009) Biomass characterization of Buddleja davidii: a potential feedstock for biofuel production. J Agric Food Chem 57:1275-1281. https://doi.org/10.1021/jf8030277

15. Imai T, Sun S, Horikawa Y et al (2014) Functional reconstitution of cellulose synthase in Escherichia coli. Biomacromolecules 15:4206-4213. https ://doi.org/10.1021/bm501217g

16. Mao Y, Liu K, Zhan C et al (2017) Characterization of nanocellulose using small-angle neutron, $X$-ray, and dynamic light scattering techniques. J Phys Chem B 121:1340-1351. https://doi.org/10.1021/acs.jpcb.6b11425 
17. Schmitt J, Calabrese V, da Silva MA et al (2018) TEMPO-oxidised cellulose nanofibrils; probing the mechanisms of gelation via small angle X-ray scattering. Phys Chem Chem Phys 20:16012-16020. https://doi. org/10.1039/C8CP00355F

18. Tsuboi M (1957) Infrared spectrum and crystal structure of cellulose. J Polym Sci 25:159-171. https://doi.org/10.1002/pol.1957.1202510904

19. Lehtio J, Sugiyama J, Gustavsson M et al (2003) The binding specificity and affinity determinants of family 1 and family 3 cellulose binding modules. Proc Natl Acad Sci 100:484-489. https://doi.org/10.1073/pnas.21265 1999

20. Liu Y-S, Baker JO, Zeng Y et al (2011) Cellobiohydrolase hydrolyzes crystalline cellulose on hydrophobic faces. J Biol Chem 286:11195-11201. https ://doi.org/10.1074/jbc.M110.216556

21. Atalla RH, Vanderhart DL (1984) Native cellulose: a composite of two distinct crystalline forms. Science 223:283-285. https://doi.org/10.1126/ science.223.4633.283

22. Delmer DP (1999) Cellulose biosynthesis: exciting times for a difficult field of study. Annu Rev Plant Physiol Plant Mol Biol 50:245-276. https://doi. org/10.1146/annurev.arplant.50.1.245

23. Kubicki JD, Yang H, Sawada D et al (2018) The shape of native plant cellulose microfibrils. Sci Rep 8:1-8. https://doi.org/10.1038/s41598-018-32211 $-\mathrm{W}$
24. Oehme DP, Downton MT, Doblin MS et al (2015) Unique aspects of the structure and dynamics of elementary $\mid \beta$ cellulose microfibrils revealed by computational simulations. Plant Physiol 168:3-17. https://doi. org/10.1104/pp.114.254664

25. Fernandes AN, Thomas LH, Altaner CM et al (2011) Nanostructure of cellulose microfibrils in spruce wood. Proc Natl Acad Sci 108:E1195-E1203. https://doi.org/10.1073/pnas.1108942108

26. Igarashi K, Uchihashi T, Koivula A et al (2011) Traffic jams reduce hydrolytic efficiency of cellulase on cellulose surface. Science 333:1279-1282. https ://doi.org/10.1126/science.1208386

27. Sugiyama J, Horikawa Y (2008) The cellulose microfibril and its polymorphs. Mokuzai Gakkaishi 54:49-57. https://doi.org/10.2488/jwrs.54.49

\section{Publisher's Note}

Springer Nature remains neutral with regard to jurisdictional claims in published maps and institutional affiliations.

\section{Submit your manuscript to a SpringerOpen ${ }^{\odot}$ journal and benefit from:}

- Convenient online submission

- Rigorous peer review

- Open access: articles freely available online

- High visibility within the field

- Retaining the copyright to your article

Submit your next manuscript at $\gg$ springeropen.com 